\title{
Continuous EEG monitoring of neonatal seizures: diagnostic and prognostic considerations
}

\author{
J CONNELL, R OOZEER, L DE VRIES, L M S DUBOWITZ, AND V DUBOWITZ \\ Department of Paediatrics and Neonatal Medicine, Royal Postgraduate Medical School, Hammersmith \\ Hospital, London
}

SUMMARY We recruited 275 full term and preterm infants into a prospective evaluation of continuous four channel electroencephalographic (EEG) monitoring in the diagnosis and prognosis of neonatal seizures. EEG seizure activity was found in 55 infants; clinical signs were completely simultaneous in only 12 of these, they were present but limited in another 20 , and were completely absent in the remaining 23 . EEG seizure activity, with or without clinical signs, were equally associated with serious cerebral lesions and with adverse clinical outcome.

The four channel EEG recording provided sufficient data on abnormality to be prognostically specific in $79 \%$ of the 43 infants who either died or had serious neurological impairment.

The technical suitability of the Oxford Medilog continuous four channel electroencephalographic (EEG) recorder for diagnostic monitoring of neonatal seizures was first reported by Eyre et al in 1983. 'Their study of prospective monitoring for the first five days of life in high risk neonates showed that there was a high incidence of EEG seizure activity in infants in whom clinical signs were either completely undetected or had apparently ceased in response to treatment with anticonvulsant drugs. In contrast, Bridges et $a l^{2}$, using the Medilog more selectively in infants in whom standard recording had already failed to show seizures and whose clinical signs had usually already ceased, found a much lower incidence of EEG seizure activity and concluded that continuous EEG monitoring was unlikely to be of diagnostic value except when clinical seizures continued. Neither of these studies commented on the prognostic significance of their observations, although the conventional multichannel EEG recording is well established as a sensitive guide to outcome in neonatal seizures. ${ }^{3-9}$

Despite its technical advantages over conventional recording, extensive use of the Medilog monitor is still expensive and time consuming. There is still a need therefore for further comprehensive evaluation of the diagnostic and prognostic potential of this technique as a guide to its optimal application in neonatal seizure disorders.

The aim of the present study was to undertake such an evaluation within the high risk population of our regional neonatal referral unit with particular attention to: the incidence of EEG seizure activity within this population; the extent to which EEG seizure activity was accompanied by clinical signs; the importance of EEG and clirical seizures in relation to concurrent clinical features and subsequent neurological outcome; the prognostic significance of EEG background activity and of quantitative analysis of seizure frequency and duration; and the establishment of criteria for optimal clinical use of the Medilog in the evaluation of neonatal seizures.

\section{Patients and methods}

During the two year period March 1985 to March 1987,275 patients were recruited to this study from 603 consecutive admissions to our regional neonatal referral unit. Admission to the study was from one of two main sources:

\section{PROSPECTIVE MONITORING (259 INFANTS)}

Subject only to the availability of recorders and of personnel to apply them, infants were monitored consecutively according to their degree of clinical risk during two separate phases. Firstly, during an initial six month period, when equal priority was given to recruitment of low risk infants to establish normal values and, secondly, during a subsequent 18 month period when high risk infants were preferentially studied.

High risk infants all had some predisposing feature; in particular, the category included those 
with congenital malformations of the central nervous system, birth asphyxia, respiratory distress, sepsis, metabolic disturbance, or evidence of intraventricular haemorrhage or leucomalacia on cranial ultrasound scan.

\section{CLINICAL SEIZURES}

Sixteen infants with seizures that were diagnosed clinically before prospective monitoring could be started were also studied; 10 had developed seizures in the unit before the monitor was applied, and six were transferred from other hospitals with established seizures.

For the purpose of this study, we defined 'neonatal' seizures as those occurring in infants up to 44 weeks' postmenstrual age, irrespective of their actual gestational age at birth.

Diagnosis of clinical seizures was based entirely on observations by nursing or medical staff. Clinical seizure types were classified according to Volpe as myoclonic, focal clonic, multifocal clonic, general tonic, or subtle..$^{10}$ Other acute associations were also based on clinical observations and findings from serial cranial ultrasound scanning performed with an Advanced Technology Laboratories Mark III sector scanner using a 5 or $7.5 \mathrm{MHz}$ transducer.

EEG recordings were performed using the Oxford Medilog 4-24 continuous four channel monitor. ${ }^{1}$ One channel was allocated to electrocardiography, ${ }^{2}$ two were allocated to the EEG, recorded with silver/silver chloride electrodes applied with collodion in the F4-P4 and F3-P3 positions (impedances $<5 \mathrm{kohms}$ ) according to the method described by Eyre et al, ${ }^{\prime}$ and the fourth channel to either respiration or a time-event marker.

Prospective early recordings were made within the first 72 hours of life in all high risk infants, and in all but three low risk infants who were monitored on the fourth day. Low risk infants were monitored for at least 24 hours and high risk infants for at least 48 hours. In infants with clinical or EEG seizure activity or both, monitoring was continued throughout these events and for at least 24 hours, or until death.

Later monitoring was performed either as routine follow up in stable infants at two to four weekly intervals while they remained within the unit, or if acute deterioration occurred in the infant's condition. In the former, recordings were made for 24 hours, and in the latter, for a minimum of 48 hours and then discontinued if no seizures were found. If seizures were detected recording was continued for at least 24 hours after seizures ceased, or until death.

Each 24 hours of data was recorded on standard $\mathrm{C}-120$ cassette tape and reviewed on the visual display unit of the Medilog system at 20 and 60 times the normal speed at scales of 1.5 and $3.0 \mathrm{~cm} / \mathrm{s}$. A compressed transcription for further analysis was made at $6 \mathrm{~cm} /$ minute using a Siemens 8 Elema Schonander ink jet recorder.

EEG recordings were analysed in relation to normal standards for gestational age established from previous studies using standard EEG recording, ${ }^{3+11} 12$ and also from our own study specifically for continuous four channel recording. ${ }^{13}$

EEG seizure activity was identified by the characteristics reported in previous studies ${ }^{3} 14$ and was analysed quantitatively for maximum daily frequency (EEG seizure activity/24 hour recording), maximum daily seizure time (number of hours/day occupied by seizures), and total duration of EEG seizure activity (days).

Background EEG was allocated to one of the following categories: normal or abnormal; if the latter they were subdivided into one of the following:

1-Excess amounts of discontinuous activity/24 hours in relation to gestational norms, but no other abnormality. This could be: (a) transient ( 24 hours only), or (b) sustained (more than 24 hours).

2-Excess discontinuity as in category 1 , plus one or more of the following: asynchrony; asymmetry; prolonged interburst interval for gestation, and low amplitude. This was further subdivided into: (a) transient (24 hours only), or (b) sustained (more than 24 hours).

3-Maximal background depression with no discernible electrical activity for more than one hour: (a) as culmination of a sequence of progressive deterioration of activity with steadily increasing interburst intervals and decreasing burst duration and amplitude, or (b) as an established finding at the first recording.

EEG recordings were analysed by two independent observers who were not regularly concerned in the clinical management of the infants studied. Results of EEG monitoring were not made available to clinical staff unless specifically requested and were then communicated without any recommendation regarding decisions on clinical management.

Assessment of outcome was based on clinical neurological examination at discharge from the unit using a standardised protocol, ${ }^{15}$ and subsequently at regular intervals between six and 24 months using the Griffiths's mental developmental scale and items from Amiel-Tison and Grenier, ${ }^{16}$ and Touwen. ${ }^{17}$ On the basis of this, infants were allocated to one of four groups: normal outcome, transient abnormalities of tone but no other abnormality, ${ }^{18}$ major neurological abnormality (cerebral palsy or mental retardation or both), or death.

To assess the relative diagnostic contribution of 
continuous Medilog monitoring, clinical signs of seizures and EEG seizure activity were correlated and allocated to one of the following categories: simultaneous EEG and clinical seizure activity, EEG seizure activity preceding or outlasting clinical events, or both, or EEG seizure activity with no clinical signs. Infants with no detectable EEG seizure activity despite a clinical diagnosis of seizures were assessed separately.

The relative importance of the above combinations of EEG and clinical seizures was assessed by comparing the acute aetiological associations and clinical neurological outcome in the infants concerned.

The prognostic function of the four channel Medilog recording was assessed by relating clinical neurological outcome of the infants studied to their background EEG activity and to quantitative aspects of seizures detected by the two EEG channels.

\section{Results}

INCIDENCE OF EEG SEIZURES (TABLE 1)

During this two year study continuous EEG monitoring was carried out in 275 infants, $45 \cdot 6 \%$ of the total 603 admitted to our unit. During the initial six months, when both high and low risk infants were equally eligible, $64 \cdot 8 \%$ of all admissions were monitored. In the following 18 months when mainly high risk infants were studied, monitoring was carried out in $38.2 \%$ of all infants admitted.

The incidence of EEG seizure activity was consistent in both the subdivided and total study periods. They were found in $20 \%$ of all infants admitted and in $25 \%$ of high risk cases in both periods. EEG seizure activity was never seen in low risk infants.
RELATION OF CLINICAL AND EEG SEIZURE ACTIVITY Of the 55 infants with EEG seizure activity, 23 $(42 \%)$ had no clinical signs, nine of them being paralysed for ventilation. There were a further 20 $(36 \%)$, in whom EEG seizure activity either preceded (by a mean of 16 hours) or outlasted (by a mean of 32 hours) the clinical signs; six of these were therapeutically paralysed. Simultaneous EEG and clinical seizures were found in only 12 infants.

Seven infants had clinically diagnosed seizures that were not detected by EEG. They showed no important differences in associated clinical features or outcome from those with EEG seizure activity and are discussed separately.

\section{COMPARATIVE ASSOCIATIONS OF CLINICAL AND EEG SEIZURE ACTIVITY \\ Postmenstrual age at onset (table 2)}

Postmenstrual age (gestational age plus chronological age) at onset of seizures was less than 32 weeks in 22 , between 32 and 37 weeks in 14, and more than 37 weeks in 19 infants.

The diagnostic yield from EEG monitoring was greatest in infants of less than 32 weeks' postmenstrual age. Of the unparalysed infants of this age, $70 \%$ had no clinical signs of EEG seizure activity. In addition, this group contained 12 out of 15 of all infants in this study who had therapeutic paralysis.

With increasing maturity, simultaneous EEG and clinical seizures became more frequent but were still found in only $47 \%$ of unparalysed infants of more than 37 weeks' postmenstrual age.

\section{Clinical seizure types (table 3 )}

Thirty two of the 55 infants with EEG seizure activity had clinical signs. There were no significant differences in the types of clinical seizures among

Table 1 Incidence of seizures among neonates and clinical risk during the study periods

\begin{tabular}{|c|c|c|c|}
\hline & \multicolumn{2}{|l|}{ Study period } & \multirow[t]{2}{*}{ Total } \\
\hline & $0-6$ months & 7-24 months & \\
\hline Total No of seizures & 20 & 35 & 55 \\
\hline No of high risk infants & 75 & 145 & 220 \\
\hline No $(\%)$ with seizures & $20(27)$ & $35(24)$ & 55 \\
\hline No of low risk infants & 34 & 21 & 55 \\
\hline No $(\%)$ with seizures & 0 & 0 & 0 \\
\hline Total No of infants monitored & 109 & 166 & 275 \\
\hline No $(\%)$ with seizures & $20(18)$ & $35(21)$ & $55(20)$ \\
\hline Total No of admissions & 168 & 435 & 603 \\
\hline No $(\%)$ with seizures & $20(12)$ & $35(8)$ & $55(9)$ \\
\hline
\end{tabular}

Expressing the number of seizures as a percentage of the total number of admissions permits estimate of the minimum incidence of seizures during these periods. 
Table 2 Extent of clinical signs of EEG seizure activity and total gestational age in 55 infants

\begin{tabular}{|c|c|c|c|c|}
\hline & \multicolumn{3}{|c|}{$\begin{array}{l}\text { Postmenstrual } \\
\text { age (weeks) }\end{array}$} & \multirow[t]{2}{*}{ Total } \\
\hline & $<32$ & $32-37$ & $>37$ & \\
\hline \multicolumn{5}{|l|}{ Total No of } \\
\hline $\begin{array}{l}\text { No with simultaneous } \\
\text { clinical signs }\end{array}$ & 1 & 3 & 8 & 12 \\
\hline $\begin{array}{l}\text { No with limited } \\
\text { clinical signs }\end{array}$ & & & & 20) \\
\hline Therapeutically paralysed & 5 & () & 1 & 6 \\
\hline Not paralysed & 2 & 5 & 7 & 14 \\
\hline \multicolumn{5}{|l|}{ No with } \\
\hline absent clinical signs & & & & 23 \\
\hline Therapeutically paralysed & 7 & 1 & 1 & 9 \\
\hline Not paralysed & 7 & 5 & 2 & 14 \\
\hline
\end{tabular}

Table 3 Extent of clinical signs of seizures and Volpe classification in 32 infants*

\begin{tabular}{llll}
\hline Type of seizure & \multicolumn{2}{l}{ Clinical signs } & Total \\
\cline { 2 - 3 } & $\begin{array}{l}\text { Simul- } \\
\text { taneous }\end{array}$ & Limited & \\
& 6 & 8 & 14 \\
Subtlc & 6 & 10 & 16 \\
General tonic & 8 & 9 & 17 \\
Multifocal clonic & 1 & 1 & 2 \\
Focal clonic & 0 & 1 & 1 \\
Myoclonic & & & \\
\hline
\end{tabular}

*17 infants had more than one type of seizure.

the 12 infants whose clinical manifestations occurred simultaneously and the 20 in whom they were limited. These 32 infants each showed between one and three seizure types. The types most commonly detected were multifocal clonic (34\%), general tonic $(32 \%)$, and subtle $(28 \%)$. Seventeen infants showed more than one seizure type. In the other 15 , subtle clinical seizure activity was the sole sign in only two cases.

\section{Aetiological associations associated with postmenstrual age}

Forty seven of the 55 infants with EEG seizure activity had one of three main aetiological associations at onset associated with postmenstrual age (table 4). Intraventricular haemorrhage was the commonest association at less than 32 weeks', leucomalacia between 32 and 37 weeks', and hypoxic-ischaemic encephalopathy at more than 37 weeks' postmenstrual age. In the other eight infants the main associations were transient flares on ultrasound imaging in three cases (all of less than 32 weeks' postmenstrual age), metabolic abnormalities in two infants of more than 37 weeks $(1$ had
Table 4 Principal aetiological associations and total gestational age in 55 infants with neonatal EEG seizure activity

\begin{tabular}{lllll}
\hline $\begin{array}{l}\text { Aetiological } \\
\text { associations }\end{array}$ & \multicolumn{2}{l}{$\begin{array}{l}\text { Postmenstrual } \\
\text { age (weeks) }\end{array}$} & $\begin{array}{l}\text { Total } \\
(n=55)\end{array}$ \\
\cline { 2 - 3 } & $\begin{array}{llll}<32 & 32-37 & >37 \\
& (n=22) & (n=14) & (n=19)\end{array}$ &
\end{tabular}

\begin{tabular}{lrrrr}
\hline $\begin{array}{c}\text { Main associations: } \\
\text { Hypoxic-ischacmic } \\
\text { encephalopathy }\end{array}$ & 1 & 4 & 14 & 19 \\
$\begin{array}{c}\text { Leucomalacia } \\
\begin{array}{l}\text { Periventricular } \\
\text { haemorrhage }\end{array}\end{array}$ & 4 & 6 & 1 & 11 \\
$\begin{array}{l}\text { Other associations: } \\
\text { Metabolic }\end{array}$ & 13 & 3 & 1 & 17 \\
Flares & 0 & 0 & 2 & 2 \\
Sepsis & 3 & 0 & 0 & 3 \\
\hline
\end{tabular}

hyponatraemia, the other a urea cycle defect), and sepsis in three infants of varying ages.

Severe cerebral lesions were present equally in those with or without clinical signs. Because the detectability of clinical signs was related to the maturity of the infant, however, intraventricular haemorrhage (the predominant lesion in those of less than 32 weeks' gestation) was also most commonly associated with EEG seizure activity without clinical expression. Conversely, simultaneous EEG and clinical seizures were most commonly found in hypoxic-ischaemic encephalopathy, which was the main aetiological association in infants of more than 37 weeks' postmenstrual age. Details of the association of seizure aetiology and degree of clinical expression of EEG seizure activity are given in table 5 .

\section{PROGNOSTIC ASSOCIATIONS}

Outcome was generally extremely poor in the 55 infants with EEG seizure activity. Thirty infants died and a further 13 survived with major neurological abnormality. Transient signs of dystonia were present in eight, and only four had a completely normal neurological outcome. Later epilepsy has so far been seen in only one infant who also has a major neurological abnormality.

\section{Outcome in clinical and EEG seizure activity (table 6)}

There was no significant difference in outcome between infants with EEG seizures only and those with simultaneous or limited clinical signs.

Prognostic importance of EEG analysis Background EEG activity (table 7)-Normal background EEG activity between seizures was usually, 
456 Connell, Oozeer, de Vries, Dubowitz, and Dubowitz

Table 5 Extent of clinical signs of EEG seizure activity and aetiological association in 55 infants

\begin{tabular}{|c|c|c|c|c|c|}
\hline \multirow[t]{2}{*}{ Clinical seizures } & \multicolumn{4}{|c|}{ Aetiological association } & \multirow[t]{2}{*}{ Total } \\
\hline & $\begin{array}{l}\text { Hypoxic-ischaemic } \\
\text { encephalopathy }\end{array}$ & Leucomalacia & $\begin{array}{l}\text { Periventricular } \\
\text { haemorrhage }\end{array}$ & Other & \\
\hline Simultaneous & 6 & 3 & 0 & 3 & 12 \\
\hline Limited & 9 & 3 & 7 & 1 & 20 \\
\hline Absent & 4 & 5 & 10 & 4 & 23 \\
\hline
\end{tabular}

Table 6 Neurological outcome and extent of clinical signs of EEG seizure activity in 55 infants

\begin{tabular}{|c|c|c|c|c|c|}
\hline \multirow[t]{2}{*}{ Clinical seizures } & \multicolumn{4}{|c|}{ Neurological outcome } & \multirow[t]{2}{*}{ Total } \\
\hline & $\begin{array}{l}\text { Normal } \\
(n=4)\end{array}$ & $\begin{array}{l}\text { Dystonia } \\
(n=8)\end{array}$ & $\begin{array}{l}\text { Major } \\
\text { abnormality } \\
(n=13)\end{array}$ & $\begin{array}{l}\text { Death } \\
(n=30)\end{array}$ & \\
\hline Simultaneous & 1 & 1 & 2 & 8 & 12 \\
\hline Limited & 2 & 1 & 5 & 12 & 20 \\
\hline Absent & 1 & 6 & 6 & 10 & 23 \\
\hline
\end{tabular}

Table 7 Background EEG activity and neurological outcome in 55 infants with neonatal EEG seizure activity

\begin{tabular}{|c|c|c|c|c|c|}
\hline \multirow{2}{*}{$\begin{array}{l}\text { Background EEG } \\
\text { activity }\end{array}$} & \multicolumn{4}{|c|}{ Neurological outcome } & \multirow[t]{2}{*}{ Total } \\
\hline & $\begin{array}{l}\text { Normal } \\
(n=4)\end{array}$ & $\begin{array}{l}\text { Dystonia } \\
(n=8)\end{array}$ & $\begin{array}{l}\text { Major } \\
\text { abnormality } \\
(n=13)\end{array}$ & $\begin{array}{l}\text { Dead } \\
(n=30)\end{array}$ & \\
\hline Normal & 3 & 3 & 2 & 2 & 10 \\
\hline \multicolumn{6}{|l|}{ Abnormal } \\
\hline (a) Transient & 0 & 3 & 0 & 2 & 5 \\
\hline (b) Persistent & 0 & 2 & 2 & 6 & 10 \\
\hline \multicolumn{6}{|l|}{$\begin{array}{l}2 \text { Excess discontinuity } \\
\text { with other abnormality: }\end{array}$} \\
\hline (a) Transient & 1 & 0 & 0 & 2 & 3 \\
\hline (b) Persistent & 0 & 0 & 7 & 1 & 8 \\
\hline \multicolumn{6}{|l|}{3 Maximal depression: } \\
\hline (a) Gradual onset & 0 & 0 & 0 & 14 & 14 \\
\hline (b) Present throughout & 0 & 0 & 2 & 3 & 5 \\
\hline
\end{tabular}

but not invariably, associated with normal neurological outcome. Excessive discontinuous EEG activity when found as an isolated abnormality was associated mainly with transient dystonia in surviving infants. Outcome became worse with increasing severity of background EEG abnormality. All those with persistently asynchronous, asymmetrical, or low amplitude traces either died or had major neurological abnormality if they survived. None of these infants had plasma phenobarbitone concentrations above the therapeutic range.

Quantitative features of EEG seizure activity-All 22 infants who exceeded one or more of the following quantitative measurements of frequency and dura- tion of EEG seizure activity either died or had major neurological abnormality if they survived: a peak frequency of more than 25 seizures/day $(n=17)$; total daily duration of seizure activity more than 30 minutes $(n=18)$; or persistence of seizure activity for more than 48 hours $(n=13)$. Less frequent or prolonged EEG seizure activity, however, as found in the other 33 infants did not necessarily guarantee survival without major neurological abnormality.

Relative prognostic contribution of background and quantitative analysis-Twenty two infants had one or more of the quantitative seizure abnormalities consistently associated with major neurological 
abnormality or death. This was additionally predictive of major abnormality or death in one infant with normal background EEG, and confirmatory in another five with background EEG abnormalities of intermediate severity. In the remaining 16 infants, quantitative analysis did not add to the prediction of major abnormality or death already made from the presence of severe background EEG abnormality.

Thirty three infants had EEG seizure activity of insufficient frequency and duration to allow definite prediction of adverse outcome, but this was further established in 12 of these by analysis of the background EEG, which showed activity constantly associated with major abnormality or death.

Thus the combined background and quantitative analysis of the four channel Medilog recording permitted certain prediction of seriously adverse outcome in 34 of the 43 infants who died, or survived with major neurological abnormality.

\section{Discussion}

Our findings confirm those of Eyre et al that neonatal seizures are more frequently diagnosed by continuous EEG monitoring than by clinical observation. In our extensive study of 275 neonates recruited during a continuous two year period, we detected an overall minimum incidence of EEG seizure activity of $20 \%$ in all infants monitored, which rose to $25 \%$ in high risk cases. It seems likely that if it had been possible to study more high risk infants for longer periods, this overall incidence would have been even higher.

The relative diagnostic contribution of the Medi$\log$ is emphasised by the limitation or absence of clinical signs in $78 \%$ of infants with EEG seizure activity. The study of Eyre $e t$ al, though reporting a much higher incidence of EEG seizure activity in a smaller study group ( 20 of 25 ), found a remarkably similar proportion to be without clinical signs: nine of $20(45 \%)$ compared with our figure of 23 of 55 $(42 \%)$. This suggests that although the incidence of neonatal EEG seizure activity may vary with the population studied, their limited association with clinical signs is a more constant feature.

The seven infants who had clinical seizures without EEG signs are of particular interest. Clinical diagnosis may have been incorrect, but this should not be assumed and it is important to consider why the Medilog may have failed to detect EEG seizure activity in these seven cases. The recordings may have been carried out at inappropriate times, which may explain three cases in which clinical events had ceased before application of the monitor. In four others, however, recording was carried out during clinical events. Severe amplitude depression of background EEG activity is well recognised from standard recording as impeding the display of electrical seizure activity. ${ }^{36}$ This was found in two infants. We cannot determine the reason in the remaining two infants, but a further possibility is that the limited number of recording channels may have failed to detect focal seizure activity.

The data provided by these two EEG channels are usually sufficient to fulfil the prognostic function already shown by standard EEG recording. ${ }^{3-9}$ This function is reliable even when anticonvulsant drugs are being given within the therapeutic range. ${ }^{19}$ Normal background EEG activity was predominantly, though not invariably, associated with normal clinical outcome. Infants with abnormal background activity rarely had a normal outcome. Those with persistently asymmetrical, asynchronous, and low amplitude activity, together with those who showed maximal background depression (either as a presenting feature or as the culmination of a progressive EEG deterioration) all either died or had major neurological abnormalities if they survived.

These important background abnormalities should be equally detectable by intermittent or by continuous monitoring. Continuous recording did, however, permit the additional detection of quantitative EEG features that were also constantly associated with major neurological abnormality or death. These were a maximum seizure frequency of more than $25 /$ day, a maximum daily seizure duration of more than 30 minutes, and a total EEG seizure duration of more than 48 hours. These quantitative factors provided helpful confirmation of prognosis based on background analysis but usually did not add to it.

Diagnosis of neonatal seizures has been regarded as important in view of their close association with severe cerebral lesions and the extremely poor outcome of infants in whom they occur. ${ }^{310}{ }^{20}$ It is not possible from this study to determine the relative contributions of the underlying brain lesion and of the seizures themselves to subsequent neurological abnormality, nor can we determine whether clinical and non-clinical seizures act through identical pathophysiological mechanisms. We did, however, find both to be equally associated with severe brain lesions and adverse neurological outcome. We suggest that equal concern should be aroused by non-clinical (EEG) as by clinical seizures, and that their detection be regarded as equally important.

In the detection of non-clinical seizures, optimal diagnostic return from limited resources may be achieved by restricting prospective monitoring to the highest risk period for seizures, which is usually 
in the first 48 to 72 hours after birth, or after acute collapse at a later stage. Priority should be given to infants with the highest potential incidence of nonclinical seizures, which in our study were those of less than 32 weeks' postmenstrual age, and neonates of any age paralysed for ventilation in whom seizures would not be apparent. Infants in whom clinical seizures have been diagnosed in the previous 24 to 48 hours may still gainfully be monitored in view of the persistence of EEG seizure activity for a mean of 32 hours after clinical events had apparently ceased.

During this diagnostic period of continuous monitoring, assessment may also be made for prognostic purposes of important quantitative aspects of EEG seizure activity. Prognostic features of EEG background activity may also be detected during this time. In infants with significant background abnormalities persisting after seizures have ceased, intermittent recordings of 1 to 2 hours/day at intervals determined by rate of resolution would be adequate for prognostic purposes.

In conclusion, we suggest that the diagnostic and prognostic value of the four channel Medilog monitor, combined with its practical advantages for use in neonatal intensive care, should make this the technique of choice for EEG evaluation of neonatal seizure disorders.

Dr Connell was supported by the Medical Research Council, and also by a locally organised clinical research grant and Milupa Ltd. Drs de Vries and LMS Dubowitz were supposed by the National Fund for Research into Crippling Diseases (Action Research for the Crippled Child)

\section{References}

1 Eyre JA, Oozeer RC, Wilkinson AR. Diagnosis of neonatal seizure by continuous recording and rapid analysis of the electroencephalogram. Arch Dis Child 1983;58:785-90.

2 Bridges SL, Ebersole JS, Ment LR, Ehrenkranz RA, Silva CG. Cassette electroencephalography in the evaluation of neonatal seizures. Arch Neurol 1986;43:49-51.

${ }^{3}$ Werner SS, Stockard JE, Bickford RG. Atlas of neonatal electroencephalography. New York: Raven Press, 1977.
4 Dreyfus-Brisac C. Neonatal electroencephalography. Reviews in Perinatal Medicine 1979;3:397-471.

${ }^{5}$ Engel R. Abnormal electroencephalogram in the neonatal period. Springfield: Thomas, 1975.

${ }^{6}$ Monod F, Dreyfus-Brisac C, Sfaello Z. Depistage et prognostic de l'etat de mal neo-natal d'apres l'etude de 150 cas. Arch Fr Pediatr 1969;26:1085-102.

7 Rose AL, Lombroso CT. A study of clinical, pathological and electroencephalographical features in 137 full-term babies with a long-term follow up. Pediatrics 1970;45:404-25.

${ }^{8}$ Rowe JC, Holmes GL, Hafford J. Prognostic value of the electroencephalogram in term and preterm infants following neonatal scizures. Electroencephalog Clin Neurophysiol 1985; 60: $183-96$

${ }^{9}$ Tharp BR, Cukier F, Monod N. The prognostic value of the electroencephalogram in preterm infants. Electroencephalog Clin Neurophysiol 1981;51:219-36.

${ }^{10}$ Volpe JJ. Neonatal seizures. Neurology of the newborn. Philadelphia: Saunders, 1987:129-59.

1 Anderson CM, Torres F, Faoro A. The EEG of the early premature. Electroencephalog Clin Neurophysiol 1985;60: 95-105.

12 Lombroso CT. Neonatal polygraphy in full-term and preterm infants: a review of normal and abnormal findings. $J$ Clin Neurophysiol 1985:2:105-55.

13 Connell JA. Oozeer R. Dubowitz V. Continuous 4-channel EEG monitoring: a guide to interpretation, with normal values, in preterm infants. Neuropediatrics 1987;18:138-45.

${ }^{14}$ Harris R, Tizard JPM. The electroencephalogram in neonatal convulsions. J Pediatr 1960;57:501-21.

15 Dubowitz LMS, Dubowitz V. The neurological assessment of the preterm and full-term infant. Clinics in developmental medicine, No 79. London: Heinemann, 1981. (Spastics International Medical Publications.)

16 Amiel-Tison C, Grenier A. Evaluation neurologique du nouveau-ne et du nourisson. Paris: Masson: 1980.

17 Touwen BLC. Examination of the child with minor neurological dysfunction. Clinics in developmental medicine, No 71. Oxford: Blackwell, 1979. (Spastics International Medical Publications.)

18 Drillien CM. Abnormal neurological signs in the first year of life in low-birthweight infants: possible prognostic significance. Dev Med Child Neurol 1972;14:575-84.

${ }^{19}$ Staudt F, Scholl ML, Coen RW, Bickford RW. Phenobarbital therapy in neonatal seizures and the prognostic value of the EEG. Neuropediatrics 1982;13:24-33.

20) Bergman I, Painter MJ, Hirsch RP, Crumrine PK, David R. Outcome in neonates with convulsions treated in an intensive care unit. Ann Neurol 1983;14:642-7.

Correspondence to Professor V Dubowitz, Department of Paediatrics and Neonatal Medicine, Hammersmith Hospital, Du Cane Road, London W12 0HS.

Accepted 3 January 1989 